\title{
The IcePod - official podcast for the Year of Polar Prediction to support MOSAiC ice drift
}

\author{
Kirstin Werner and Sara Pasqualetto \\ WMO WWRP International Coordination Office for Polar Prediction, Alfred Wegener Institute Helmholtz Centre for Polar \\ and Marine Research, Bremerhaven, Germany
}

Correspondence: Kirstin Werner (kirstin.werner@awi.de) and Sara Pasqualetto (sara.pasqualetto@awi.de)

Published: 20 May 2021

In support of the MOSAiC 1-year ice drift, the World Meteorological Organization's International Coordination Office for Polar Prediction launched a podcast entitled The IcePod. In monthly episodes, MOSAiC participants talked about their field experience and personal impressions on board the largest-ever expedition to the Arctic.

Since the German research icebreaker RV Polarstern set sail for the central Arctic Ocean in September 2019, the MOSAiC expedition has brought significant international attention to polar research: the largest-ever Arctic scientific campaign became the hot topic of various international TV news and radio programmes, it made it to the front page of print magazines and online journals, and the Alfred Wegener Institute's in-house photographer Esther Horvath won the World Press Photo Award for capturing that stunning moment of a curious mother polar bear and her cub exploring the ice camp lightened only by the ship's pale spotlights.

MOSAiC certainly was not only for scientists, but the media and public around the globe were closely following. What has been going on in the icy surroundings of Polarstern hosting about 100 people at a time? Working and living aboard this solitary vessel frozen to an ice floe in the Arctic Ocean, at times being further away from humankind than the International Space Station, has been a once-in-a-lifetime experience that by October 2020 almost 450 people of 37 different nationalities had brought back to their homes. Driven by their passion for the Arctic's vast environment, their love for adventures, their curiosity, inquiring minds and spirit of research, they were the lucky ones, keen to explore the field of the Arctic climate with the ultimate goal of understanding in detail the environmental processes intertwining the deep ocean with the sea-ice cover and atmospheric layers at high elevation, during polar day and polar night.
MOSAiC is one of the many projects that are working towards an improved understanding of atmospheric and sea-ice processes, as currently coordinated by the World Meteorological Organization's initiative to improve weather and seaice forecasts in polar regions. The Polar Prediction Project is a 10-year endeavour to enable a significant improvement in environmental prediction capabilities for the polar regions and beyond, on timescales from hours to seasons (Jung et al., 2016; see also Werner, 2021, on Year of Polar Prediction (YOPP) in this issue). Joint activities of an international community of scientists, forecasters and experts at numerical weather centres and stakeholder groups operating in polar regions are coordinated through the Year of Polar Prediction, the flagship activity of the Polar Prediction Project. With periods of intensive observing, modelling, prediction, verification, user engagement and education activities, the scope of the Year of Polar Prediction goes significantly beyond classic weather forecasting and includes, in particular, sea-ice forecasting and the incorporation of seasonal timescales.

In support of MOSAiC as a major project endorsed by the Year of Polar Prediction, The IcePod came about: it is a series of digital audio episodes launched with the start of MOSAiC in autumn 2019. On a monthly basis, colleagues who have participated in the biggest Arctic research expedition gave first-hand insights into their life and work on board Polarstern surrounded by a frozen field laboratory but also talked about their work and career development in polar research. With this, the podcast has aimed to amplify communication of the science activities within the Year of Polar Prediction during MOSAiC and beyond, providing a platform for scientists to share their unique experience being on a research vessel such as RV Polarstern (Alfred-WegenerInstitut Helmholtz-Zentrum für Polar- und Meeresforschung, 

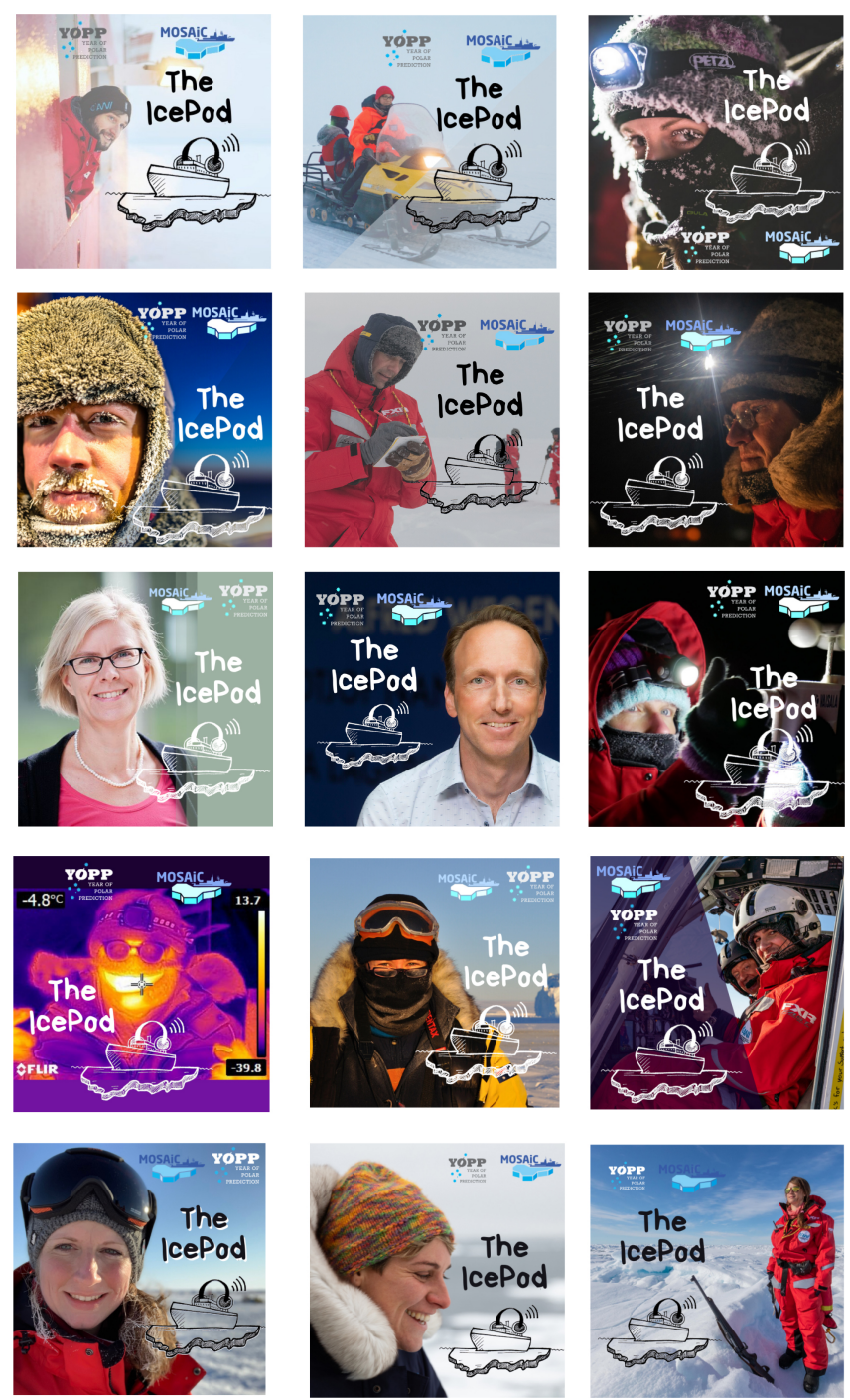

Figure 1. By early 2021, 10 full episodes, four bonus episodes and one live episode of the Year of Polar Prediction podcast The IcePod were produced (photo sources, from upper left to lower right, Sam Cornish, Thomas Rackow, Stefan Hendricks, Mario Hoppmann, Esther Horvath, Eva Dalin, Martina Buchholz, Julia Wenzel, Michael Gallagher, Peter Hargreaves, Christian Rohleder, Stefanie Arndt, Marcel Nicolaus, Lianna Nixon).

2017). In a general effort to enhance communication and knowledge transfer for the Year of Polar Prediction, the podcast has put a personal face to polar research to make a close connection between science and society.

To date, 10 full episodes, four bonus episodes, one live episode and two trailers have been published. This season of The IcePod podcast has seen the manifold participation of scientists and professionals involved in the different research areas of MOSAiC: climate scientist Thomas Rackow and master student Thea Schneider joined the MOSAiC School on board RV Akademik Fedorov and helped set up the distributed network around RV Polarstern (episodes 1 and 2);

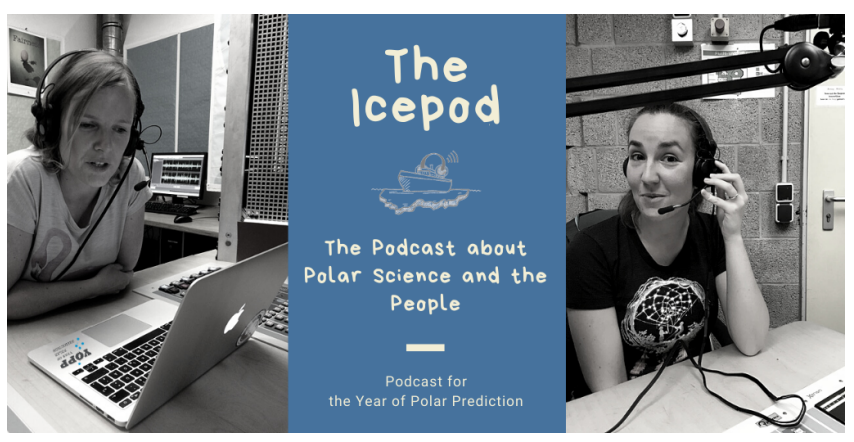

Figure 2. The IcePod is produced in cooperation with Radio Weser.TV Bremerhaven (photo: Sara Pasqualetto, Kirstin Werner).
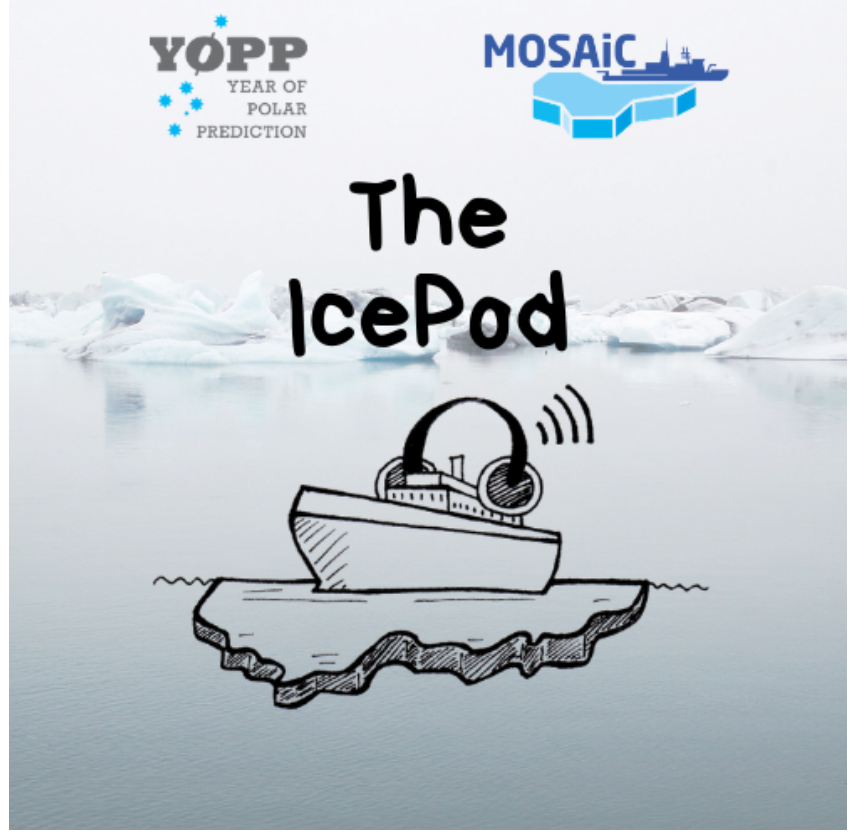

Figure 3. Logo of The IcePod, season 1 (source: Sara Pasqualetto).

sea-ice scientists Stefan Hendricks and Gunnar Spreen explained how Remote Sensing City was built on the ice camp and how satellite techniques can be applied to learn about the central Arctic sea ice during polar night (episodes 3 and 4); meteorologists Taneil Uttal (episode 6) and Robert Hausen (episode 7) supported Team Atmosphere, which launched regular weather balloons, measured conditions in different layers of the atmosphere, and looked into the weather forecast that was key for every decision of whether to explore the sea-ice situation aboard the helicopter or not; sea-ice scientist Stefanie Arndt led Team Ice during the challenging coldest leg of MOSAiC with lots of uncertainty due to very dynamic ice conditions (episode 8).

But science does not happen in a vacuum: real-life challenges and dynamics have greatly impacted the work of research on MOSAiC - the podcast also provides insights by 
MOSAiC project manager Anja Sommerfeld to help organise a year-long campaign in the central Arctic and how to find a way to exchange expedition teams when a pandemic extends travel restrictions also to the Arctic Ocean (episode 5). MOSAiC data manager Antonia Immerz explained how to coordinate the huge number of data generated during the expedition year and how to store and eventually make the data accessible for everyone (episode 9). As a member of the Logistics and Safety Team, Laura Schmidt (episode 10) informed on her experience during leg 4 how to ensure a safe working environment for the people out on the ice floe.

In addition, MOSAiC coordinator Markus Rex shared his very personal perspective on the greatest challenges, nicest moments and biggest surprises during MOSAiC Leg 1 (bonus episode 1). Other bonus episodes have delved into particular ongoing YOPP activities, such as the processbased YOPPsiteMIP evaluation of forecast skill and efforts to provide improved polar weather and sea-ice forecast services to society (bonus episode 2 with Gunilla Svensson and bonus episode 3 with Thomas Jung). A few more upcoming episodes of The IcePod's first season will continue to feature MOSAiC leaders and participants including co-coordinator Matthew Shupe and Polarstern captain Thomas Wunderlich.

Data availability. The IcePod can be found on several of the main podcast platforms (e.g. Apple Podcasts, https://podcasts.apple.com/us/podcast/the-icepod/ id1480223567?uo=4\&at=1019W2\&ct=search_results, last access: 3 March 2021; Spotify, https://open.spotify.com/show/ OuNGiEiVxPZGfb1dtzmoof, last access: 3 March 2021; Castbox, https://castbox.fm/channel/The-IcePod-id2373890?country=us,

last access: 3 March 2021). It is produced with the technical support of the Bremerhaven local community radio station Radio Weser.TV. Episodes are, in fact, also broadcasted through the radio station, featuring a personal set of music titles chosen by the interview guest. Further information about The IcePod can be found at https://theicepodcast.home.blog/ (last access: 3 March 2021).

Author contributions. Editorial responsibility of The IcePod podcast is with $\mathrm{KW}$ and SP, who have equally contributed to this article.

Competing interests. The authors declare that they have no conflict of interest.
Acknowledgements. We would like to thank the guests of this podcast for sharing their fascinating insights with us. We very much enjoyed producing each of the episodes and learning about the MOSAiC expedition MOSAiC20192020, Project_ID: AWI_PS122_00. This is a contribution to the Year of Polar Prediction (YOPP), a flagship activity of the Polar Prediction Project (PPP), initiated by the World Weather Research Programme (WWRP) of the World Meteorological Organization (WMO). We acknowledge the WMO WWRP for its role in coordinating this international research activity. We are grateful for the support of Radio Weser.TV Bremerhaven and the AWI Communications and Media Relations, and we thank Anja Sommerfeld for carefully reading and fact-checking the manuscript.

Review statement. This paper was edited by Bernhard Diekmann.

\section{References}

Alfred-Wegener-Institut Helmholtz-Zentrum für Polar- und Meeresforschung: Polar Research and Supply Vessel POLARSTERN Operated by the Alfred-Wegener-Institute, Journal of Large-Scale Research Facilities, 3, A119, https://doi.org/10.17815/jlsrf-3-163, 2017.

Jung, T., Gordon, N. D., Bauer, P., Bromwich, D. H., Chevallier, M., Day, J. J., Dawson, J., Doblas-Reyes, F., Fairall, C., Goessling, H. F., Holland, M., Inoue, J., Iversen, T., Klebe, S., Lemke, P., Losch, M., Makshtas, A., Mills, B., Nurmi, P., Perovich, D., Reid, P., Renfrew, I. A., Smith, G., Svensson, G., Tolstykh, M., and Yang, Q.: Advancing Polar Prediction Capabilities on Daily to Seasonal Time Scales, B. Am. Meteorol. Soc., 97, 1631-1647, 2016.

Werner, K.: Year of Polar Prediction - enhance observations to provide improved forecasts in polar regions, Polarforschung, this issue, 2021. 